\title{
Growth and Welfare Effects of Macroprudential Regulation
}

DOI:

$10.1017 / \mathrm{S} 1365100517001080$

\section{Document Version}

Accepted author manuscript

Link to publication record in Manchester Research Explorer

\section{Citation for published version (APA):}

Agenor, P-R. (2018). Growth and Welfare Effects of Macroprudential Regulation. Macroeconomic Dynamics. https://doi.org/10.1017/S1365100517001080

\section{Published in:}

Macroeconomic Dynamics

\section{Citing this paper}

Please note that where the full-text provided on Manchester Research Explorer is the Author Accepted Manuscript or Proof version this may differ from the final Published version. If citing, it is advised that you check and use the publisher's definitive version.

\section{General rights}

Copyright and moral rights for the publications made accessible in the Research Explorer are retained by the authors and/or other copyright owners and it is a condition of accessing publications that users recognise and abide by the legal requirements associated with these rights.

\section{Takedown policy}

If you believe that this document breaches copyright please refer to the University of Manchester's Takedown Procedures [http://man.ac.uk/04Y6Bo] or contact uml.scholarlycommunications@manchester.ac.uk providing relevant details, so we can investigate your claim.

\section{OPEN ACCESS}




\title{
Growth and Welfare Effects of Macroprudential Regulation
}

\author{
Pierre-Richard Agénor* \\ Forthcoming, Macroeconomic Dynamics
}

\begin{abstract}
This paper studies the growth and welfare effects of macroprudential regulation in an overlapping generations model of endogenous growth with banking and agency costs. Indivisible investment projects combine with informational imperfections to create a double moral hazard problem à la Holmström-Tirole and a role for bank monitoring. When the optimal monitoring intensity is endogenously determined, an increase in the required reserve ratio (motivated by systemic risk considerations) has conflicting effects on investment and growth. On the one hand, requiring banks to put away a fraction of the deposits that they receive reduces the supply of loanable funds. On the other, a higher required ratio raises incentives to save and mitigates banks' incentives to monitor, thereby lowering monitoring costs and freeing up resources to increase lending. In addition, it may mitigate the systemic risk externality associated with excessive leverage. This trade-off can be internalized by choosing the required reserve ratio that maximizes growth and welfare. However, the risk of disintermediation means that in practice financial supervision may also need to be strengthened, and the perimeter of regulation broadened, if the optimal ratio is relatively high.
\end{abstract}

JEL Classification Numbers: E44, G28, O41.

${ }^{*}$ School of Social Sciences, University of Manchester, United Kingdom, and Centre for Growth and Business Cycle Research. I am grateful to participants at various seminars and conferences, and especially the Associate Editor and two anonymous referees, for many helpful comments. King Yoong Lim provided able research assistance. Financial support from the DFID-ESRC Growth Research Programme, under Grant No. ES/L012022/1, is gratefully acknowledged. The views expressed in this paper are my own. 


\section{Introduction}

The growth effects of financial volatility, and ways to mitigate them, have been largely absent from discussions regarding the implications of the global financial crisis for financial and regulatory reform. Indeed, the debate has focused almost exclusively on the implications of financial volatility for short-term economic stability and on the short-run benefits of financial regulation - especially macroprudential policies, which take a systemic approach in addressing financial vulnerabilities - in terms of mitigating procyclicality of the financial system and dampening short-run fluctuations in credit and output.

However, understanding the longer run effects of financial regulation is essential because of the potential dynamic trade-off associated with the fact that regulatory policies, designed to reduce procyclicality and the risk of financial crises, could well be detrimental to economic growth — despite contributing to a more stable environment in which agents can assess risks and returns associated with their investment decisions. In low-income countries, where sustaining high growth rates is essential to increase standards of living and escape poverty, understanding the terms of this trade-off is particularly important. These countries are often characterized by an underdeveloped formal financial system, and thus limited opportunities to borrow and smooth shocks. ${ }^{1}$ The real effects of financial volatility on firms and individuals can therefore be not only large but also highly persistent, thereby translating into not only transitory drops in output but also adverse, and long-lasting, effects on growth. ${ }^{2}$ In such conditions, the benefits of regulatory measures aimed at promoting financial stability could be fairly substantial.

Yet, regulatory constraints may have a large and persistent effect on the risk-taking incentives of financial intermediaries - because, for instance, they induce structural shifts in banks' portfolio composition, in the form of a move away from risky assets toward safer investments. More generally they may constrain their capacity to lend. The consequence may be high interest rate spreads, suboptimal levels of borrowing by

\footnotetext{
${ }^{1}$ See for instance Mecagni et al. (2015) for a discussion of the state of banking in Africa.

${ }^{2}$ These adverse growth effects are consistent with the evidence showing that financial liberalization, to the extent that it is accompanied by greater financial volatility, may not contribute much to promoting growth; see for instance Misati and Nyamongo (2012) and the overview by Fowowe (2013). The latter study, in particular, highlights the need to strengthen prudential regulation to enhance the benefits of financial liberalization. However, the potential adverse effects of prudential regulation itself are not discussed.
} 
entrepreneurs to finance investment, and shifts of activity to less-regulated financial intermediaries, all of which exerting potentially adverse effects on growth and welfare. A key question therefore is to determine the optimal degree of financial regulation that internalizes this trade-off. Moreover, because the institutional environment in low-income countries is often weak, a related issue is what type of financial regulatory instruments should be implemented.

The literature on these issues, however, remains scant. One of the first analytical contributions in this area is Van den Heuvel (2008), who studied the welfare effects of bank capital requirements in a standard growth setting. ${ }^{3}$ In line with the foregoing discussion, he argues that capital adequacy requirements may have conflicting effects on welfare. On the one hand, by inducing banks to hold less risky portfolios, they mitigate the probability of a financial crisis, which enhances welfare. ${ }^{4}$ On the other, by inducing a shift in banks' portfolios away from risky, but more productive, investment projects, toward safer, but less productive, projects, it may hamper economic growth and have an adverse effect on welfare. Capital requirements entail therefore a trade-off between banking efficiency and financial stability; as capital levels rise, there are costs, in terms of increased lending spreads or reduced loan volumes. However, a limitation of that paper is that, because growth is exogenous, the implications of this trade-off for long-run growth, and the extent to which policy can internalize it, cannot be fully explored.

Using an overlapping generations (OLG) endogenous growth model with financial intermediation, this paper contributes to the literature on the growth and welfare effects of macroprudential regulation in several ways. In the model, the production of capital is subject to a dual moral hazard problem in the sense of Holmström and Tirole (1997). Entrepreneurs, who need external funds to finance their investment projects, may be tempted to choose less productive projects (shirk) with higher non-verifiable returns. But although bank monitoring mitigates the moral hazard problem associated with the behavior of entrepreneurs, the fact that banks use deposits from households to fund their loans also creates an incentive for them to shirk when monitoring is

\footnotetext{
${ }^{3}$ Recent contributions by Barnea et al. (2015) and Begenau (2015) also focus on capital requirements. However, their analysis is at the business cycle frequency, rather than growth per se.

${ }^{4}$ Note that, as argued for instance by Dewatripont and Tirole (2012), equity capital may be equally effective in reducing incentives for excessive risk taking by banks. For a further analysis of the links between prudential regulation and risk-taking in an endogenous growth setting see Agénor and Pereira da Silva (2017).
} 
costly. In addition, banks have access to an imperfect monitoring technology, which can only detect high-shirking projects. Even when monitored by his bank, therefore, an entrepreneur may still choose to run a project with low shirking intensity. The optimal financial contract ensures that he has the incentive to choose instead efficient (and socially valuable) projects only.

However, the model presented here departs from the Holmström-Tirole paradigm in three important ways. First, households cannot lend directly to producers; intermediated finance occurs only through banks. This assumption is more appropriate for a low-income environment, where capital markets are underdeveloped - if not entirely absent. Second, to mitigate the second source of moral hazard and increase incentives for depositors to fund intermediation, banks are compelled to hold reserve requirementsa prudential instrument that has been used extensively in developing countries and is now part of the liquidity requirement guidelines under the Basel III arrangement (see Basel Committee on Banking Supervision (2013)). In the context of the model, reserve requirements operate essentially as partial deposit insurance. Third, the intensity of monitoring, which affects private returns from shirking, is endogenously determined.

The key insights from the analysis are as follows. When the monitoring costs that financial intermediaries face are exogenous, an increase in the required reserve ratio - motivated by the desire to improve incentives to deposit savings in the financial system, and possibly also to mitigate the systemic risk externality associated with excessive leverage - has unambiguously negative effects on investment and economic growth because the net effect is a reduction in the supply of loanable funds. However, when monitoring intensity is endogenously determined, an increase in the required reserve ratio has conflicting effects on investment, growth and welfare. The reason is that, when monitoring intensity is endogenous, the adverse effect on lending may be offset by the fact that a higher required reserve ratio also mitigates banks' incentives to monitor. In turn, this is because the fact that a higher required reserve ratio tends to lower investment (as noted earlier), and thus borrowers' expected income, also calls for a reduction in the intensity of monitoring in order to increase the borrowers' nonverifiable private benefits and keep the entrepreneur's expected income constant. This reduction in monitoring intensity translates into lower monitoring costs, which frees up resources to increase loans and mitigates the adverse direct effect of a higher required reserve ratio on lending. The trade-off between promoting financial stability and fostering 
economic growth can be internalized by choosing optimally the required reserve ratio. Nevertheless, if the optimal policy calls for reserve requirements to be set at relatively high levels, it may foster disintermediation away from the banking sector and toward less regulated channels, which in turn may distort markets, weaken financial stability, and reduce investment and growth. The risk of disintermediation means therefore that in practice financial supervision may also need to be strengthened, and the perimeter of regulation broadened, when more aggressive macroprudential policies are implemented.

The analysis also shows that it is optimal to impose high required reserve ratios on banks when their ability to monitor borrowers is weak. This result is consistent with the evidence suggesting that reserve requirements tend to be set on average at higher levels in developing countries (where informational frictions are more prevalent and banks face more difficulty in discriminating between good and bad credit risks) compared to more advanced countries.

The remainder of the paper is organized as follows. Section 2 describes the model, taking the intensity of monitoring as well as the required reserve ratio as given. It dwells in part on the extension of the Holmström-Tirole model to a growth and financial development setting by Chakraborty and Ray (2006), but incorporates the three major differences mentioned earlier. ${ }^{5}$ In addition, monitoring outlays are pecuniary in nature and their opportunity cost affects incentive constraints. The optimal financial contract is characterized in Section 3. The equilibrium level of investment is determined in Section 4, whereas the balanced growth equilibrium path is characterized in Section 5. Autonomous changes in monitoring intensity and the required reserve ratio are studied in Section 6. In Section 7, optimal monitoring is analyzed and the growth- and welfare-maximizing values of the required reserve ratio are solved for numerically. The last section provides some concluding remarks and discusses perspectives for further research.

\section{Economic Environment}

The economy consists of a continuum of risk-neutral agents who live for two periods, adulthood and old age. These agents are of two types: an exogenous fraction $n \in$

\footnotetext{
${ }^{5}$ Chakraborty and Ray (2006) focused on the link between growth and the evolution of marketbased and bank-based financial systems. They did not discuss financial regulation or the optimal setting of policy instruments.
} 
$(0,1)$ are workers, the remaining are entrepreneurs. Without loss of generality, $n$ is normalized to 0.5 and the measure of each type of agents to one. Population is constant. Domestic agents can access the international capital market but access is asymmetric: they can lend (deposit funds) but they cannot borrow. ${ }^{6}$ There are two production sectors and a continuum of banks of measure 1, which channel funds from savers to borrowers. ${ }^{7}$ For simplicity, each worker and each entrepreneur are randomly matched with a single bank. There is also a financial regulator, whose role is to set reserve requirements.

\subsection{Workers and Entrepreneurs}

A worker (or saver) is born with one unit of time in adulthood, which it supplies inelastically to the labor market. The entire wage income, $w_{t}$, is saved in adulthood; thus, a generation- $t$ worker's lifetime utility depends only upon second-period consumption. ${ }^{8}$ For simplicity, a worker's utility is linear in wage income. As in Gale (2004) for instance, workers do not have access to a monitoring technology and therefore do not lend directly to producers; they invest all their savings (or first-period income) either in bank deposits at home, $d_{t}$, or abroad. Arbitrage implies that both investments yield the same (gross) return, $R^{D}>1$, which is set exogenously.

Each entrepreneur $j$, with $j \in[0,1]$, is also born with one unit of labor time in adulthood, which is used to operate a technology that converts, after one period, units of the final good into a marketable capital good. Entrepreneurs therefore do not consume either in the period when they are born. They are altruists and derive utility from their old-age consumption, $c_{t+1}^{j, E}$, and bequests made to their offspring, $b_{t+1}^{j}$. Specifically, a typical generation- $t$ entrepreneur's preferences are given by the 'warm-glow' utility function:

$$
U_{t}^{j, E}=\left(c_{t+1}^{j, E}\right)^{\beta}\left(b_{t+1}^{j}\right)^{1-\beta},
$$

\footnotetext{
${ }^{6}$ Foreign intermediaries do not lend directly to domestic agents because they do not have the same ability as domestic lenders to legally enforce the terms of loan contracts in domestic courts. The assumption of asymmetric access to world capital markets is consistent with the evidence for many developing countries (see for instance Agénor (2012)).

${ }^{7}$ The fundamental reason why banks exist in this setting is because they provide monitoring services to depositors, avoiding therefore duplication costs. An alternative rationale could be, as in Bhattacharya et al. (1997) for instance, that the formation of banks is an equilibrium mechanism for providing insurance against relocation shocks - which play the same role as liquidity preference shocks in the standard Diamond-Dybvig framework - in a setting where spatial separation limits communication among agents.

${ }^{8}$ The analysis also abstracts from subsistence consumption; see Strulik (2010) for a discussion.
} 
where $\beta \in(0,1) .^{9}$

Let $z_{t+1}^{j}$ denote entrepreneur $j$ 's realized income in old age, which is derived later. Given Cobb-Douglas preferences in (1), optimal decision rules are linear in $z_{t+1}^{j}$. Thus, entrepreneur $j$ leaves to his offspring a constant proportion of his realized income in old age:

$$
b_{t+1}^{j}=(1-\beta) z_{t+1}^{j},
$$

the remaining fraction being consumed, so that $c_{t+1}^{j, E}=\beta z_{t+1}^{j}$.

\section{$2.2 \quad$ Production Sectors}

The production sectors in the economy consist of a final goods sector and a capital goods sector, which supplies inputs to firms producing final goods.

\subsubsection{Final Goods Sector}

Competitive firms produce the final good (which can be either consumed or invested) by combining labor and capital goods. The underlying private technology exhibits constant returns in capital and labor inputs:

$$
Y_{t}=A_{t} N_{t}^{1-\alpha} K_{t}^{\alpha}
$$

where $\alpha \in(0,1), N_{t}$ is the number of workers, $K_{t}=\int_{0}^{1} K_{t}^{j} d j$ is the aggregate capital stock, and $A_{t}$ a productivity parameter.

There is an Arrow-Romer type externality associated with the capital-labor ratio $k_{t}=K_{t} / N_{t}$, so that

$$
A_{t}=A k_{t}^{1-\alpha}
$$

Combining (3) and (4) yields, in standard fashion, a linear relationship between (aggregate) production per worker, $y_{t}$, and capital per worker: ${ }^{10}$

$$
y_{t}=A k_{t}
$$

Final goods producers operate in competitive output and input markets so that equilibrium capital rental and wage rates, $R_{t}^{K}$ and $w_{t}$, are determined by their marginal

\footnotetext{
${ }^{9}$ Altruism among workers can be readily incorporated in the model without qualitatively altering any of the core results.

${ }^{10}$ See Jensen (2017) for a deeper discussion of the underlying foundations of the $A K$ model illustrated in $(5)$.
} 
product:

$$
R^{K}=\alpha A, \quad w_{t}=(1-\alpha) A k_{t} .
$$

To ensure that the gross return $R^{K}>1$, the restriction $A>1 / \alpha$ is imposed.

\subsubsection{Capital Goods Sector}

Each capital good $j$ is produced by a single entrepreneur. Because (as noted earlier) generations of entrepreneurs are interconnected through a bequest motive, firm $j$ is effectively infinitely lived. At any given period in time, the adult member of entrepreneurial family $j$ is the owner-manager of that firm, converting units of the final good into capital with a one-period lag. In each period, capital goods become available before production of final goods starts.

Each entrepreneur invests an indivisible amount $q_{t}^{j}$, which is taken as given for the moment. The investment is risky. When it fails, it yields nothing. When it succeeds, it produces a verifiable amount of capital equal to

$$
K_{t+1}^{j}=q_{t}^{j}
$$

where for simplicity there is a one-to-one relationship between flows and stocks, and capital goods fully depreciate upon use.

As long as $q_{t}^{j}>b_{t}^{j}$, entrepreneur $j$ has to raise the difference $l_{t}^{j}=q_{t}^{j}-b_{t}^{j}$ from banks. All entrepreneurs produce the same type of capital good and are price takers. The common return they earn from renting out their capital is $R^{K}>1$, the (constant) marginal product of capital in a competitive equilibrium, given by (6).

\subsection{The Financial Sector}

Financial intermediaries consist of banks, which obtain (as noted earlier) their supply of loanable funds from workers' deposits and use them to lend to entrepreneurs for the purpose of building capital. However, deposits are subject to a reserve requirement imposed by the regulator. The rationale is that there is no deposit insurance system (or, if it exists, it is not credible) so banks must be forced to hold liquid assets in order to provide partial insurance and maintain financial stability. This is the sense in which reserve requirements are macroprudential in nature. ${ }^{11}$ As noted earlier, for ease

\footnotetext{
${ }^{11}$ An early literature, which includes Bhattacharya et al. (1997), studies the role of reserve requirements in Sidrauski-type monetary growth models. However, the focus there is on the role of reserves
} 
of exposition, each bank randomly receives deposits from one saver only and lends to one entrepreneur only.

Banks are endowed with a technology (specialized skills) that allows them to inspect a borrowing entrepreneur's cash flow and balance sheet, observe the owner-manager's activities, and ensure that the entrepreneur conforms to the terms or covenants agreed upon in the financial contract. ${ }^{12}$ Monitoring, although imperfect, helps to address a standard agency problem that banks face in lending to entrepreneurs.

Specifically, as in Holmström and Tirole (1997), suppose that each entrepreneur is allowed to choose between three types of investment projects, which differ in their success probability and the nonverifiable private benefits that they generate. ${ }^{13}$ Suppose also that (as noted earlier) the entrepreneur must raise funds amounting to $q_{t}^{j}-b_{t}^{j}>0$ for his investment. When the project succeeds, it realizes the amount of capital given in (7), with a return $R^{K}$, which is verifiable at no cost. But when the project fails, it produces nothing; there is no remaining liquidation value. The moral hazard problem arises from the fact that the probability of success depends on an unobserved action taken by the entrepreneur. The unobserved action can be interpreted as his choice of how to spend $q_{t}^{j}$. He can spend it on an efficient (good) project that results in success with probability $\pi^{H}<1$ (and returning therefore $R^{K} q_{t}^{j}$ ), but uses up all of $q_{t}^{j}$. Or, he can spend it on one of two inefficient projects that may not succeed. One of these alternatives, a low-moral hazard project, costs $q_{t}^{j}-v q_{t}^{j}$, where $v \in(0,1)$, leaving $v q_{t}^{j}$ for the entrepreneur to appropriate. The other inefficient choice, a high-moral hazard project, costs $q_{t}^{j}-V q_{t}^{j}$, where $V \in(0,1)$, thereby leaving $V q_{t}^{j}$ in private benefits. Both inefficient projects carry the same probability of success, $\pi^{L}<\pi^{H}$, but it is assumed that $0<v<V<1$. Hence, the entrepreneur will always prefer the high-moral hazard project over the low-moral hazard one. ${ }^{14}$ Only the efficient project is, however,

in raising the inflation tax base and facilitating the financing of fiscal deficits - in effect, a case of financial repression. In addition, these models feature exogenous growth, and are therefore not suited to address the issue of growth- and welfare-maximizing reserve requirements, as is done in this paper.

${ }^{12}$ Households do not possess this technology, or even if they do, are too disparate to effectively use it. Thus, in standard fashion (see Diamond (1984)), banks act as delegated monitors. Note that the monitoring activities considered here differ from ex post monitoring in the costly state verification literature, where lenders monitor when the project outcome is realized and only when the borrower defaults. Accordingly, the cost of monitoring in that literature is more akin to a bankruptcy cost.

${ }^{13}$ Private benefits are nontransferable and capture the idea that the entrepreneur gets some kind of non-monetary return from some projects. A common interpretation is that they capture effort. Lower effort is clearly a benefit to the entrepreneur, but (as discussed next) it also leads to a lower probability of success.

${ }^{14}$ While entrepreneurs consume in the second period of life only, they invest in the first. As in 
economically viable and thus socially valuable; to ensure that's the case, the following standard conditions are imposed:

Assumption 1. $\pi^{H} \alpha A-R^{D}>0>\pi^{L} \alpha A+V-R^{D}$.

Intuitively, these conditions state that the expected net surplus per unit invested in a good project is positive, while that of a high-moral hazard project is negative even after the private benefit is accounted for. ${ }^{15}$

Monitoring partially resolves the agency problem and reduces the entrepreneur's opportunity cost of being diligent. By monitoring borrowers, banks eliminate the highmoral hazard project but not the low-moral hazard one. Thus, because misrepresenting high levels of effort can be achieved only by performing some level of effort, an entrepreneur is left with two choices under monitoring: selecting the efficient project or the low-moral hazard project. At the same time, monitoring involves a pecuniary cost for the bank, representing a nonverifiable amount $\gamma \in(0,1)$ per unit invested. Hence, bank monitoring will be an optimal arrangement only if the gains from resolving agency problems outweigh the monitoring costs.

\section{Optimal Financial Contract}

In this setting, the structure of the optimal financial contract depends on whether or not an entrepreneur chooses to be diligent, which in turn depends on his incentives to do so and outside monitoring by the bank. For its part, the bank chooses either to lend the full amount needed to invest in the production of capital goods (net of the borrower's initial wealth, $q_{t}^{j}-b_{t}^{j}$ ) or not at all. Because workers delegate to the bank the task of monitoring entrepreneurs, banks must ensure that the return that savers obtain is sufficiently high for them to deposit their funds in the first place. This section characterizes the optimal contract when entrepreneurs behave diligently and choose only good projects.

Specifically, the optimal contract is such that no party (due to limited liability)

Chakraborty and Ray (2006), it is assumed that the private benefits generated by negligent behavior cannot be invested. Instead, they have to be stored away for one period in the form of goods. Such storage yields zero net return and is unobservable. In addition, stored goods cannot be seized by lenders if the investment project fails.

${ }^{15}$ Because $v<V$, this restriction implies that the condition $0>\pi^{L} \alpha A+v-R^{D}$ also holds. Note that a sufficient condition for Assumption 1 to hold is $1 \leq \pi^{L} \alpha A$, or equivalently that the highest benefit associated with the high-moral hazard project has a smaller value than the social cost that it imposes in the form of a lower success probability. 
earns anything when the project fails, whereas when it succeeds the gross return, $R^{K}$, is distributed so that

$$
R_{t+1}^{B}+R_{t+1}^{E}+R_{t+1}^{W}=R^{K}
$$

where $R_{t+1}^{B}, R_{t+1}^{E}$ and $R_{t+1}^{W}$ denote the gross returns to the bank, the entrepreneur, and the saver, respectively.

Entrepreneur $j$ invests $q_{t}^{j}$ in the good project as long as it yields an incentive compatible return. As noted earlier, given that the banker always monitors if it lends, an entrepreneur will not choose the high-moral hazard project. The good project returns $R_{t+1}^{E} q_{t}^{j}$ with probability $\pi^{H}$, whereas the expected return to the low-moral hazard project is $\pi^{L} R_{t+1}^{E} q_{t}^{j}+v q_{t}^{j}$, that is, the sum of the (expected) market return plus the private return. The incentive compatibility constraint for the entrepreneur is thus $\pi^{H} R_{t+1}^{E} q_{t}^{j} \geq \pi^{L} R_{t+1}^{E} q_{t}^{j}+v q_{t}^{j}$, or equivalently

$$
R_{t+1}^{E} \geq \frac{v}{\Delta \pi}
$$

where $\Delta \pi=\pi^{H}-\pi^{L}$.

The incentive compatibility constraint for the bank relates to the fact that it engages in monitoring. The monitoring cost is proportional (at the rate $\gamma$, as noted earlier) to the size of the project. Thus, the bank's incentive constraint for monitoring, and thus to engage in lending, requires that its expected return on a good project, net of monitoring outlays (valued at their opportunity cost, $R^{D}$ ), be greater than or equal to the expected return of a low-moral hazard project without monitoring, that is, $\pi^{H} R_{t+1}^{B} q_{t}^{j}-\gamma R^{D} q_{t}^{j} \geq \pi^{L} R_{t+1}^{B} q_{t}^{j}$, or equivalently

$$
R_{t+1}^{B} \geq \frac{\gamma R^{D}}{\Delta \pi}
$$

The participation constraint for workers requires that their expected return from the project, which is the weighted sum of the return when the project succeeds (and the bank is repaid, with probability $\pi^{H}$ ) and the value of reserve requirements $\mu d_{t}^{j}$ when it fails (and so does the bank, with probability $1-\pi^{H}$ ), to be at least equal to the risk-free return on deposits:

$$
\pi^{H} R_{t+1}^{W} q_{t}^{j}+\left(1-\pi^{H}\right) \mu d_{t}^{j} \geq R^{D} d_{t}^{j}
$$

where $\mu \in(0,1)$ is the required reserve ratio set by the financial regulator. Thus, in this setting, reserves held with the regulator are used to compensate depositors if the bank 
fails and operate fundamentally like a partial deposit insurance scheme - providing therefore, as discussed later, a rationale for prudential regulation. ${ }^{16}$

Free entry and competition compel banks to offer contracts whose objective is to maximize the representative entrepreneur's expected share of the return, $\pi^{H} R_{t+1}^{E} q_{t}^{j}$, subject to the incentive compatibility constraints (9) and (10), the participation constraint (11), and the bank's resource constraint

$$
l_{t}^{j} \leq(1-\mu) d_{t}^{j}-\gamma q_{t}^{j}
$$

and non-negativity constraints $R_{t+1}^{i} \geq 0$, where $i=E, B, W$. Equation (12) indicates that loans cannot exceed deposits (adjusted for required reserves), net of monitoring costs.

Given perfect competition, in equilibrium the entrepreneur earns just enough to choose the efficient project, and the lender is paid just enough to have an incentive to monitor. The incentive constraints (9) and (10) therefore hold with equality,

$$
R_{t+1}^{E}=\frac{v}{\Delta \pi}, \quad R_{t+1}^{B}=\frac{\gamma R^{D}}{\Delta \pi},
$$

so that, using (8),

$$
R_{t+1}^{W}=R^{K}-\left(\frac{v+\gamma R^{D}}{\Delta \pi}\right)
$$

Thus, when there is a greater incentive to divert funds ( $v$ is larger), or when monitoring is more costly ( $\gamma$ is higher), the payment share of the entrepreneur or the bank must be larger (and that of savers correspondingly smaller), to be incentive compatible subject to $R_{t+1}^{W}>0$.

Substituting (14) in (11), holding with equality, the value of deposits in bank $j$ is given as

$$
d_{t}^{j}=\frac{\pi^{H}}{R^{D}-\left(1-\pi^{H}\right) \mu}\left[R^{K}-\left(\frac{v+\gamma R^{D}}{\Delta \pi}\right)\right] q_{t}^{j},
$$

where $R^{D}-\left(1-\pi^{H}\right) \mu>0$, given that $\pi^{H}, \mu<1$. As noted earlier, workers save all their wage income. To abstract from credit rationing and distributional considerations, it is assumed that $w_{t}>d_{t}^{j}$ for all $i$ and that the difference (wage minus deposits) is invested abroad at the rate $R^{D}$. Thus, total income that workers consume in old age is $R^{D} w_{t}$.

\footnotetext{
${ }^{16}$ For simplicity, I assume that the regulator maintains reserves in liquid form. If instead it invests them abroad, at the rate $R^{D}$, the term $\left(1-\pi^{H}\right) \mu d_{t}^{j}$ in (11) would be replaced by $\left(1-\pi^{H}\right) R^{D} \mu d_{t}^{j}$. However, given that in this setting the deposit rate is set on world markets, this has no significant impact on the results.
} 


\section{Equilibrium investment}

In equilibrium, only good projects are selected and all entrepreneurs obtain credit from a (matched) bank in period $t$. Using the bank's resource constraint (12), holding with equality, and $l_{t}^{j}=q_{t}^{j}-b_{t}^{j}$ to eliminate $d_{t}^{j}$ in (15) yields

$$
\frac{R^{D}-\left(1-\pi^{H}\right) \mu}{1-\mu}\left[(1+\gamma) q_{t}^{j}-b_{t}^{j}\right]=\pi^{H}\left[R^{K}-\left(\frac{v+\gamma R^{D}}{\Delta \pi}\right)\right] q_{t}^{j},
$$

which can be rewritten as

$$
q_{t}^{j}=\left\{1+\gamma-\frac{(1-\mu) \pi^{H}}{R^{D}-\left(1-\pi^{H}\right) \mu}\left[R^{K}-\left(\frac{v+\gamma R^{D}}{\Delta \pi}\right)\right]\right\}^{-1} b_{t}^{j}=\Phi b_{t}^{j},
$$

Equation (16) determines the equilibrium level of investment, for initial wealth $b_{t}^{j}$ given. To ensure that $\Phi$ is positive, the following condition is imposed:

Assumption 2. $\pi^{H} R^{K}-(1+\gamma)\left[R^{D}-\left(1-\pi^{H}\right) \mu\right] /(1-\mu)<\pi^{H}\left(v+\gamma R^{D}\right) / \Delta \pi$.

This condition means that the expected per unit surplus of a good project, $\pi^{H} R^{K}$, net of the cost of banking activity — which consists of interest paid to depositors and the opportunity cost of monitoring, with the deposit rate adjusted for the tax on financial intermediation imposed by reserve requirements, and of the benefit to savers of these requirements being returned to them if the bank fails - is less than the expected sum of the shares paid to the entrepreneur and the banker to ensure that they behave diligently.

In addition, to ensure that $\Phi$ is greater than unity (to ensure positive borrowing) the following restriction is also imposed:

Assumption 3. $\pi^{H} R^{K}-\gamma\left[R^{D}-\left(1-\pi^{H}\right) \mu\right] /(1-\mu)>\pi^{H}\left(v+\gamma R^{D}\right) / \Delta \pi$.

This condition can be interpreted as requiring the probability of success of the good project, $\pi^{H}$, to be sufficiently large relative to the probability of success of the inefficient projects, $\pi^{L}$.

Using (16), the equilibrium level of loans is given by

$$
l_{j}^{j}=q_{t}^{j}-b_{t}^{j}=(\Phi-1) b_{t}^{j} .
$$

From (16) and (17), the following proposition can be established:

Proposition 1. With constant monitoring intensity, the equilibrium levels of lending and investment are decreasing in the required reserve ratio, $\mu$. 
This proposition is easy to establish by showing that indeed $\partial \Phi / \partial \mu<0$. It results directly from the fact that higher required reserves reduce the bank's loanable funds, and thus all else equal the (expected) income from lending. This occurs despite the fact that it raises incentives for savers, as can be inferred from (15) - an issue that is further discussed later. ${ }^{17}$

Figure 1 shows the determination of the equilibrium, for an initial level of wealth equal to $b_{0}^{j}$. The equilibrium level of investment is at $D$, and the equilibrium level of loans at $C$. By construction, the distance $B D$ is equal to the distance $A C$ (or, equivalently, $A B$ is equal to $C D$ ).

Let $z_{t+1}^{j}$ denote entrepreneur $j$ 's second-period income; in equilibrium, from (13) and (16),

$$
z_{t+1}^{j}=\left(\frac{v \Phi}{\Delta \pi}\right) b_{t}^{j}
$$

which shows that entrepreneurial income is also linear in wealth.

\section{Balanced Growth Equilibrium}

Because optimal loan contracts ensure that all entrepreneurs behave diligently, they all borrow from the banking system. In a symmetric equilibrium, the wealth of the representative entrepreneur - and thus aggregate wealth, given that the population of entrepreneurs is fixed and normalized to unity - evolves according to

$$
b_{t+1}=(1+g) b_{t},
$$

where the constant growth rate $1+g$ is defined as, using (2) and (18),

$$
1+g=\frac{(1-\beta) v \Phi}{\Delta \pi}
$$

As implied by (16), equilibrium investment is linear in entrepreneurial wealth. Because all entrepreneurs behave diligently, equations (7) and (16) imply that in a symmetric equilibrium the aggregate stock of capital in $t+1$ is given by

$$
K_{t+1}=\Phi b_{t},
$$

\footnotetext{
${ }^{17}$ Let $R_{t+1}^{L}$ denote the loan rate charged by the bank if the project succeeds. In equilibrium, only good projects are selected and banks make zero (expected) profits, so that $\pi^{H} R_{t+1}^{L} l_{t}^{j}=R^{D} d_{t}^{j}$. Using (12) to substitute out for $d_{t}^{j}=(1-\mu)^{-1}\left(l_{t}^{j}+\gamma q_{t}^{j}\right)$ yields $\pi^{H} R_{t+1}^{L}=(1-\mu)^{-1} R^{D}\left(1+\gamma q_{t}^{j} / l_{t}^{j}\right)$. Using (16) and (17) to substitute out for $q_{t}^{j} / l_{t}^{j}$ yields the equilibrium loan rate as $R_{t+1}^{L}=(1-\mu)^{-1} R^{D}[1+$ $\gamma \Phi /(\Phi-1)] / \pi^{H}$, so that $R_{t+1}^{L}>R^{D}$ and, given that $\partial \Phi / \partial \mu<0, \partial R_{t+1}^{L} / \partial \mu>0$. Thus, equivalently, the reduction in lending is due to the increase in the cost of borrowing induced by an increase in the required reserve ratio.
} 
which, using (19), yields $K_{t+1}=(1+g) K_{t}$. Aggregate capital grows at the same rate as entrepreneurial wealth. From (17), credit also grows at the same rate as investment and wealth.

From (5), because the aggregate production function is linear in capital, the growth of output mimics that of capital as well. Similarly, given that from (6) the equilibrium wage rate is linear in capital, and that second-period consumption of workers is equal to $R^{D} w_{t}$, worker consumption grows at the same rate as the rate of growth of the capital stock. For entrepreneurs, as noted earlier in equilibrium all of them access credit markets and borrow from banks; from (18), and because $c_{t+1}^{E}=\beta z_{t+1}$, their consumption is linear in wealth and hence grows at the same rate as workers' consumption.

\section{Autonomous Policy Changes}

Consider first the effect of a permanent reduction in the unit monitoring cost, $\gamma$, perhaps through better contract enforcement, and suppose that the private benefit of the low-moral hazard project is decreasing and convex in monitoring intensity, so that $v=v(\gamma)$, with $v^{\prime}<0, v^{\prime \prime} \geq 0$, and $\lim _{\gamma \rightarrow \infty} v^{\prime}(\gamma)=0$. Thus, monitoring not only helps to eliminate the high-moral hazard project, it also mitigates the private benefit that can be derived from (and thus the incentives to engage in) low-moral hazard projects. The following proposition can then be easily established:

Proposition 2. A reduction in monitoring intensity, $\gamma$, when the private benefit of the low-moral hazard project is decreasing and convex in $\gamma$, has ambiguous effects on investment and the steady-state growth rate.

The direct impact of lower monitoring intensity can be gauged from (13) and (14). A reduction in $\gamma$ raises $v(\gamma)$ and the per-unit project return $R_{t+1}^{E}$ that must be promised to entrepreneurs, because it increases their ability to divert resources. At the same time it lowers $R_{t+1}^{B}$, the per-unit share of the project's return that must be allocated to bankers in order for them to find it worth monitoring as intensively as promised. Consequently, equation (14) shows that the change in the per-unit share of project return that accrues to workers supplying loanable funds is ambiguous in general, given that $\gamma$ and $v(\gamma)$ move in opposite directions. The net effect depends on the efficiency of the monitoring technology. From (16) and (20), the effect on the optimal level of investment and output growth is thus also ambiguous. If $v^{\prime}$ is relatively small, the impact on the banker's return will dominate. This will lead to higher deposits, greater 
borrowing, and higher investment by all entrepreneurs. A lower unit monitoring cost therefore increases the growth rate.

Consider now a permanent increase in the required reserve ratio, $\mu$. In the present setting, the rationale for this policy is related to the fact that, by forcing banks to hold liquid reserves, the regulator provides partial deposit insurance to savers - thereby mitigating the risk that they incur. Indeed, the participation constraint of workers (11) accounts for the fact that required reserves are returned to savers when the bank fails, an event that occurs with probability $1-\pi^{H}$. As a result, and as can be directly inferred from (15), a higher required reserve ratio - for a given level of investment-improves savers' incentives to fund bank lending through deposits.

At the same time, however, the increase in the required reserve ratio reduces the supply of loanable funds and leads to lower lending and investment (as noted in Proposition 1), and consequently a lower steady-state growth rate (see (20)). The drop in investment also mitigates the direct benefits of a higher ratio in terms of increased incentives to depositors. ${ }^{18}$ If the net effect on deposits is positive, a trade-off emerges between financial stability considerations and economic growth. These results can be summarized in the following proposition:

Proposition 3. An increase in the required reserve ratio, $\mu$, with constant monitoring intensity, unambiguously lowers investment and the steady-state growth rate, despite directly improving incentives to hold deposits through partial insurance.

A further potential benefit of regulation emerges in this model if it is assumed that systemic risk takes the form of a negative externality that relates the leverage ratio of borrowers to the probability of success of good projects - and thus the probability of bank failure. When entrepreneurs are highly leveraged, they may be less diligent in ensuring that their project is successful - even when they are monitored; and if banks cannot improve monitoring intensity, the financial system may become more vulnerable to adverse shocks. This view is consistent with the evidence relating episodes of financial instability to excessive private borrowing and unsustainable credit growth. ${ }^{19}$

\footnotetext{
${ }^{18}$ Substituting (20) in (15) and differentiating the resulting expression shows that $d d_{t}^{j} / d \mu \gtrless 0$; in principle, therefore, the net impact on deposits is ambiguous, although the indirect effect is unlikely to dominate, based on reasonable parameter values. Note also that in this setting changes in the required reserve ratio have no effect on the deposit rate, which is set on world capital markets. In a closed economy a higher ratio would lead to a lower deposit rate, which would unambiguously tend to reduce deposits.

${ }^{19}$ See Taylor (2015) for a review of the recent literature. In a contribution building also on the Holmström-Tirole model, but focusing on short-run fluctuations, Christensen et al. (2011) relate the
} 
Formally, this view can be captured by relating $\pi^{H}$ inversely to the leverage ratio that prevails in a symmetric equilibrium, $l_{t} / b_{t}$. To fix ideas, suppose that

$$
\pi^{H}=1-\pi_{0}^{H}\left(\frac{l_{t}}{b_{t}}\right)
$$

where $\pi_{0}^{H}>0$ can be interpreted as measuring the strength of the externality imposed by individual bank behavior on the degree of riskiness of the financial system as a whole. From (17), the equilibrium leverage ratio is given by

$$
\frac{l_{t}}{b_{t}}=\Phi-1
$$

Suppose now that the initial leverage ratio (and thus the probability of bank failure) is considered too high by the regulator. From Proposition 1 it can readily be established that, at the initial value of $\pi^{H}$, an increase in $\mu$ lowers the leverage ratio, and consequently raises $\pi^{H}$, to an extent that depends on the magnitude of $\pi_{0}^{H}$. Thus, the probability of bank failure, $1-\pi^{H}$, falls, mitigating financial fragility as expected.

However, the increase in $\pi^{H}$ also affects bank incentives to lend. Indeed, when the likelihood of a good project succeeding goes up, a lender's expected return also increases; all else equal, maintaining the incentive to monitor requires a lower gross return for banks (see (10)). This leads also to a higher gross return to savers (see (14)), which compounds the incentive effect (alluded to earlier) of a higher required reserve ratio on deposits, thereby increasing further the supply of loanable funds. The net impact on investment depends on the total effect on $\Phi$, which is given by, using (22) and (23),

$$
\frac{d \Phi}{d \mu}=\frac{\partial \Phi}{\partial \mu}+\left(\frac{\partial \Phi}{\partial \pi^{H}}\right)\left(\frac{\partial \pi^{H}}{\partial \mu}\right)=\frac{\partial \Phi}{\partial \mu}\left[1-\pi_{0}^{H}\left(\frac{\partial \Phi}{\partial \pi^{H}}\right)\right] .
$$

As shown earlier, $\partial \Phi / \partial \mu<0$. From (16) it can also be established that $\partial \Phi / \partial \pi^{H}>$ 0 . Thus, the net effect on investment is positive if $\pi_{0}^{H}\left(\partial \Phi / \partial \pi^{H}\right)>1$ and negative otherwise - the latter case prevailing if $\pi_{0}^{H}$ is not too large. ${ }^{20}$

These results can be summarized in the following proposition:

Proposition 4. An increase in the required reserve ratio, $\mu$, with constant monitoring intensity and with a systemic externality that relates the probability of successful projects to borrowers' leverage ratio, may lower investment and the steady-state growth rate, despite improving incentives to save through partial deposit insurance and reducing the probability of bank failure.

probability of bank failure (defined also as $1-\pi^{H}$ ) to the aggregate credit-to-output ratio.

${ }^{20}$ Note also that from $(20), \pi^{H}$ also has a direct effect on growth, independently on its effect on $\Phi$. This complicates further the calculation of the net effect on growth 
The thrust of the foregoing discussion is thus that, even in the presence of an externality that may enhance the benefits of macroprudential regulation, an increase in the required reserve ratio motivated solely by financial stability considerations may create a trade-off with economic growth. The issue that is addressed next is whether the financial regulator can internalize this trade-off by setting the required reserve ratio optimally.

\section{Optimal Policy}

In the foregoing analysis, both the intensity of monitoring and the required reserve ratio were taken as given. In the first part of this section the intensity of monitoring is endogenized and solved for optimally by the representative bank. In the second the growth- and welfare-maximizing values of the required reserve ratio, taking into account its impact on the optimal degree of monitoring intensity, are derived. For tractability, the focus is on the case where $\pi^{H}$ is constant, so that the macroprudential rationale for adjusting the required reserve ratio relates solely to improved incentives for depositors. This also makes it easier to convey the intuition behind the results.

\subsection{Optimal Monitoring Intensity}

The optimal choice of $\gamma$, with $v=v(\gamma)$, must also maximize the entrepreneur's expected payoff, $\pi^{H} R_{t+1}^{E} q_{t}^{j}$, at the equilibrium level of investment. Using (13) and (16) for $R_{t+1}^{E}$ and $q_{t}^{j}$ yields

$$
\pi^{H} R_{t+1}^{E} q_{t}^{j}=\frac{\pi^{H} v(\gamma)}{\Delta \pi} \Phi b_{t}^{j}
$$

To derive a tractable analytical solution to the problem, suppose as in Haavio et al. (2015) for instance, that $v(\gamma)$ takes the following functional form:

$$
v(\gamma)=\left\{\begin{array}{cl}
\Gamma \gamma^{-\varepsilon /(1-\varepsilon)} & \text { if } \gamma>\gamma_{m} \\
v_{m} & \text { if } \gamma \leq \gamma_{m}
\end{array}\right.
$$

where $\Gamma>0, v_{m}>0, \varepsilon \in(0,1)$, and $\gamma_{m}>0$. The first row of equation (25) shows that $v(\gamma)$ is differentiable and strictly convex for $\gamma>\gamma_{m}$ and that the monitoring technology is the more efficient the larger $\Gamma$ is, or the smaller $\varepsilon$ is. Thus, as before, the private benefit is decreasing in the intensity of monitoring. The second row implies that there is a minimum efficient scale for monitoring investment projects or an upper 
bound for the private benefit. This upper bound ensures that the net rate of return on a bad project is negative even for low levels of $\gamma$.

Substituting equation (25) in (24) with $b_{t}^{j}$ given, the first-order condition for this problem is

$$
\frac{-\varepsilon}{(1-\varepsilon) \gamma \Phi}-\left\{1+\frac{(1-\mu) \pi^{H}}{\left[R^{D}-\left(1-\pi^{H}\right) \mu\right] \Delta \pi}\left[\frac{-\varepsilon}{1-\varepsilon} \frac{v(\gamma)}{\gamma}+R^{D}\right]\right\}=0
$$

which can be solved to give

$$
\gamma^{*}=\varepsilon\left\{1+\frac{(1-\mu) \pi^{H} R^{D}}{\left[R^{D}-\left(1-\pi^{H}\right) \mu\right] \Delta \pi}\right\}^{-1}\left[\frac{(1-\mu) \pi^{H}}{R^{D}-\left(1-\pi^{H}\right) \mu} \alpha A-1\right] .
$$

Intuitively, a change in $\gamma$ has conflicting effects on the entrepreneur's expected income. A higher $\gamma$ reduces directly the private benefit $v(\gamma)$, which tends to lower the entrepreneur's expected income for $\Phi$ given. In addition, there are two indirect effects, operating through $\Phi$ : on the one hand, the increase in $\gamma$ raises monitoring costs, which requires from (13) an increase in the bank's expected income in order to maintain its incentive to monitor; on the other, savers' expected income may also increase - depending on the sign of $v+\gamma R^{D}$ in (14) - which may in turn, as can be inferred from (15), raise the level of deposits for a given level of investment. The first effect tends to lower $\Phi$ and the second to increase it. Consequently, the overall effect on the entrepreneur's expected income is ambiguous. The optimal solution balances out these different effects. ${ }^{21}$

Assuming that an interior solution exists (so that $\gamma>\gamma_{m}$ ), equation (26) yields directly the following proposition:

Proposition 5. The optimal level of monitoring intensity, when the private benefit of the low-moral hazard project is decreasing and convex in that variable, is decreasing in the required reserve ratio, $\mu$, and increasing in the elasticity of the monitoring technology, $\varepsilon$.

Intuitively, a more efficient monitoring technology magnifies the benefit of monitoring and raises the optimal intensity of monitoring; this lowers the private benefit of the low-moral hazard project. However, as implied by Proposition 2, this does not necessarily promote investment and growth. More importantly for the issue at stake, a higher required reserve ratio reduces the optimal intensity of monitoring. Intuitively,

\footnotetext{
${ }^{21}$ For $\gamma$ to be positive in $(26)$ requires $(1-\mu) \pi^{H} \alpha A>R^{D}-\left(1-\pi^{H}\right) \mu$. This condition is imposed numerically in the simulations reported later on.
} 
from Proposition 1 a higher $\mu$ tends to lower $\Phi$, and thus the equilibrium level of investment, which tends to reduce the entrepreneur's expected income. This must be offset by reducing the intensity of monitoring, in order to increase the private benefit and keep the entrepreneur's expected income constant. Thus, macroprudential regulation alters the incentives of banks to monitor and lend.

From equations (16), (20) and (26) it can also be established that:

Proposition 6. An increase in the required reserve ratio, $\mu$, with monitoring intensity set optimally and with $v^{\prime}<0$, has ambiguous effects on investment and the steady-state growth rate.

Thus, in contrast to the results reported in Proposition 3, when monitoring intensity is endogenous and set optimally, it is possible for an increase in the required reserve ratio to have now a positive effect on investment and growth. The reason is that now, as noted earlier, a higher required reserve ratio tends to reduce the bank's incentive to monitor, which reduces in turn monitoring costs and may increase deposits - above and beyond the direct incentive effect on savers - and the ability to lend. As a result $\Phi$ and the equilibrium level of investment may increase. As discussed next, these results are important to study the determination of the optimal required reserve ratio.

\subsection{Optimal Required Reserve Ratio}

A natural benchmark for the optimal required reserve ratio set by the financial regulator is the solution that maximizes either growth or welfare. In the first case, it is obvious that, given Proposition 3, the growth-maximizing value of $\mu$, given by $d \ln (1+g) / d \mu=$ 0 , is 0 if $v$ is constant, and regardless of whether $\gamma$ is set optimally or not. Indeed, given that reserve requirements unambiguously lower investment and growth, it is optimal not to impose them in the first place if the goal is to maximize growth.

By contrast, when $v^{\prime}<0$ and $\gamma$ is set optimally, a non-trivial solution may exist. From (20), this solution is obtained by solving the condition

$$
\frac{d \ln (1+g)}{d \mu}=\frac{d \ln v\left(\gamma^{*}\right)}{d \mu}+\frac{d \ln \Phi\left(\mu, \gamma^{*}\right)}{d \mu}=0
$$

where $v\left(\gamma^{*}\right)$ and $\gamma^{*}$ are given by (25) and (26), and with

$$
\ln \Phi\left(\mu, \gamma^{*}\right)=-\ln \left\{1+\gamma^{*}-\frac{(1-\mu) \pi^{H}}{R^{D}-\left(1-\pi^{H}\right) \mu}\left[\alpha A-\frac{v\left(\gamma^{*}\right)+\gamma^{*} R^{D}}{\Delta \pi}\right]\right\} .
$$

However, the resulting expression is too complex to be solved analytically and will be solved numerically later on. 
Consider next the welfare-maximizing solution. Suppose that the financial regulator is far sighted and benevolent, in the sense that it takes into account the welfare of all future generations of entrepreneurs and savers. To calculate the welfare for each generation, recall that there is no consumption in adulthood and that given (1), the indirect utility function of entrepreneurs in old age is linear in income, so that $U_{t+1}^{E}=$ $\beta^{\beta}(1-\beta)^{1-\beta} z_{t+1}$. Similarly, for workers, the indirect utility function takes the linear form $c_{t+1}^{W}=R^{D} w_{t}$, given that all income (including interest) is consumed in old age. Recall also that each group represents half of the population. Thus, the welfare criterion is the equally weighted within each generation, but discounted, sum of log-utilities across an infinite sequence of generations (see De la Croix and Michel, 2002, p. 91):

$$
\mathcal{W}_{t}=\sum_{h=0}^{\infty} \Lambda^{h}\left\{0.5 \ln \beta^{\beta}(1-\beta)^{1-\beta} z_{t+h+1}+0.5 \ln R^{D} w_{t+h}\right\},
$$

where $\Lambda \in(0,1)$ is the regulator's discount factor. From (6) and (18), along the balanced growth path,

$$
\mathcal{W}_{t}=\sum_{h=0}^{\infty} \Lambda^{h}\left\{0.5 \ln \left[\frac{\beta^{\beta}(1-\beta)^{1-\beta} v \Phi \tilde{b}_{t+h}}{\Delta \pi}\right]+0.5 \ln R^{D}(1-\alpha) A \tilde{k}_{t+h}\right\}
$$

From (19) and (21), $b_{t}$ and $k_{t}$ grow at the same rate along the balanced growth path. Thus, along the steady-state equilibrium path, $\tilde{x}_{t+h}=(1+g)^{t+h} x_{0}$, where $x=b, k$. Substituting these results in (29), and ignoring constant terms, yields

$$
\mathcal{W}_{t}=\sum_{h=0}^{\infty} \Lambda^{h}\left\{0.5\left[\ln v\left(\gamma^{*}\right)+\ln \Phi\left(\mu, \gamma^{*}\right)\right]+(t+h) \ln (1+g)\right\} .
$$

Given that $\Lambda<1, \mathcal{W}_{t}$ is strictly concave and bounded, and the choice set is convex and compact. Thus, the optimization problem $\max _{\mu} \mathcal{W}_{t}$ has a single solution. Approximating (30) gives $^{22}$

$$
\begin{gathered}
\mathcal{W} \simeq 0.5 \frac{\ln v\left(\gamma^{*}\right)}{1-\Lambda}+\frac{\Lambda}{(\Lambda-1)^{2}} \ln (1+g) \\
-\frac{0.5}{1-\Lambda} \ln \left\{1+\gamma^{*}-\frac{(1-\mu) \pi^{H}}{R^{D}-\left(1-\pi^{H}\right) \mu}\left[\alpha A-\frac{v\left(\gamma^{*}\right)+\gamma^{*} R^{D}}{\Delta \pi}\right]\right\},
\end{gathered}
$$

with $1+g, v\left(\gamma^{*}\right)$, and $\gamma^{*}$ solved for from the solution of (20), (25) with $\gamma^{*}>\gamma_{m}$, and (26), respectively. The optimal value of $\mu$ is the one for which $d \mathcal{W} / d \mu=0$ is

\footnotetext{
${ }^{22}$ This approximation uses the standard result $\sum_{h=0}^{\infty} h x^{h}=x /(x-1)^{2}$ when $|x|<1$, together with $x=\Lambda$ and $t=0$.
} 
obtained. However, once again the resulting expression is too complex to allow an explicit analytical solution.

Accordingly, a numerical evaluation is performed. The recursive system of equations (20), (25) with $\gamma>\gamma_{m}$, and (26) is solved, subject to Assumptions 1 to 3, for values of $\mu \in(0,1)$. The optimal value of $\mu$ is thus the one that maximizes either growth (equation (27)) or welfare (equation (31)).

To perform the simulations, the following benchmark values are used: $\alpha=0.3$, $A=5, \beta=0.55, \pi^{H}=0.95, \pi^{L}=0.2, \varepsilon=0.05, R^{D}=1.02$, and $\Gamma=0.1$. Assuming an annual discount factor of 0.04 and interpreting a period as 30 years yields an intergenerational discount factor $\Lambda=0.308$. These values are either fairly standard $(\alpha$ and $\Lambda$ for instance) or reasonable for a low-income economy. In particular, the base scenario assumes that the elasticity of the monitoring technology is fairly low. In this benchmark case it can be verified that $\mu^{*}=0.189, \gamma^{*}=0.0035$, and $v\left(\gamma^{*}\right)=0.135$. For this set of values, and as long as $0.135<V<0.7$, the restriction $A>1 / \alpha$ and Assumptions 1 to 3 are all satisfied. Thus, the optimal required reserve ratio in the benchmark case is fairly high, even compared to actual values for low-income countries.

It is also worth assessing how the optimal required reserve ratio changes when structural parameters vary - especially, given the focus of this paper, with respect to the monitoring technology parameter $\varepsilon$. Specifically, Figure 2 shows the results for $\varepsilon$ varying over the interval $(0.05,0.2)$; for values higher than 0.22 , one (or several) of the Assumptions 1 to 3 is (are) not satisfied. Regardless of the value of $\varepsilon$, the growth- and welfare-maximizing solutions are practically identical, because in explaining changes in welfare, growth effects tend to dominate in the present setting. ${ }^{23}$ Thus, only the growth-maximizing solution value is shown in the figure. The key result that the figure illustrates is an inverse relationship between the optimal value of $\mu$ and $\varepsilon$. For $\varepsilon=0.1$ and 0.15 for instance, the optimal values of $\mu$ are 0.148 and 0.097 , respectively. Intuitively, a higher elasticity of the monitoring technology raises the optimal monitoring intensity, as implied by Proposition 5 and as shown in the figure. In turn, the increase in $\gamma$ reduces the private benefit of the low-moral hazard project, $v(\gamma)$, which helps to promote investment and growth. At the same time, however, higher monitoring costs reduce the bank's capacity to lend, which tends to reduce investment and growth. To

\footnotetext{
${ }^{23}$ The reason is the magnitude of the coefficient of $\ln (1+g)$ in $(31)$, compared to the coefficients of the other two terms in that expression.
} 
maximize growth and welfare, it is thus optimal to reduce $\mu$ as $\varepsilon$ increases. The idea that it is desirable to impose high required reserve ratios on banks when their ability to monitor borrowers is weak is broadly consistent with the evidence (see Agénor and Pereira da Silva (2016) and Cerutti et al. (2017)) which suggests that the use of reserve requirements remains widespread in developing countries and tend to be set on average at higher levels than in developed countries.

\section{Conclusion}

Using an OLG model with banking, I examined in this paper the growth and welfare effects of macroprudential regulation. In the model, financial intermediation is subject to a dual moral hazard problem in the tradition of Holmström and Tirole (1997). This problem, which arises from the information asymmetry between borrowers and lenders, makes it unfeasible to write incentive contracts contingent on the production technology chosen by borrowers. To ensure prudent investment of the funds that they lend, banks must monitor borrowers. A monitoring bank is always successful in preventing entrepreneurs from using some of the proceeds of their loans to pay for unproductive activities. However, given that it is costly to monitor, banks must be provided with adequate incentives to do so. In addition, I assumed that households cannot lend directly to producers, that banks are subject to financial regulation, and that the intensity of monitoring, which affects private returns from shirking, is endogenously determined.

The analysis focused on reserve requirements as the instrument of financial regulationa prudential instrument that has been used extensively in both developing countries and has been made part of the liquidity requirement guidelines under Basel III. It was first shown that the direct effect on investment and economic growth of higher reserve requirements, aimed at improving incentives for depositors or mitigating systemic financial risks by reducing private sector leverage, may be negative when monitoring intensity is taken as given. However, the same policy has conflicting effects on growth when monitoring intensity is endogenized because it also affects banks' incentives to monitor. The trade-off between promoting financial stability and fostering economic growth can therefore be internalized by setting the required reserve ratio at its optimal value. Simple numerical experiments were used to determine that value and how it depends on the parameters characterizing the economy. The analysis showed, in par- 
ticular, that there is an inverse relationship between the optimal required reserve ratio and the efficiency of monitoring.

An important caveat to the analysis relates to the fact that the model did not account explicitly for the possibility that even though reserve requirements are set optimally, their level may be so high (as shown in the benchmark experiment) that they may foster disintermediation away from the formal banking system and toward less regulated channels. Even though the impact of this shift on investment and growth may be muted, it may exacerbate systemic risks. The risk of regulatory arbitrage means therefore that financial sector supervision may also need to be strengthened, and the boundary of regulation broadened, when macroprudential policy reforms are implemented. This is an important message for policymakers.

The analysis presented here can be extended in a number of directions. First, a better integration of short-run stabilization issues and longer-term considerations would be useful. In particular, if prudential regulation can mitigate business cycle volatility and reduce uncertainty about future economic conditions, it may have a permanent, positive effect on private investment and economic growth. These effects should also be internalized when setting policy instruments. Second, the focus of the present analysis was on a single macroprudential instrument. In addition to the fact that reserve requirements have been used extensively (as noted earlier), this focus is justified by the fact that in a weak institutional environment (as is often the case in developing countries, especially the poorest ones), macroprudential rules aimed at preserving financial stability should not be overly complicated. However, it would be useful to consider other instruments in this setting, such as capital requirements and a leverage ratio, and solve jointly for the optimal levels of these instruments.

Third, the analysis in this paper found no conflict between maximizing growth and maximizing welfare in setting the required reserve ratio. However, this result would not necessarily hold in a more general setting where risk-taking behavior by lenders and borrowers is endogenous, or where the implementation of prudential rules involves a pecuniary cost that must be financed by distortionary taxes. For instance, while prudential regulation could mitigate incentives for lenders to finance investment in risky technologies, thereby reducing financial risks, mitigating growth volatility, and thus improving welfare, it could also reduce the average growth rate. In such conditions, the use of a single instrument is not sufficient to maximize both growth and welfare; 
another instrument (in the form perhaps of a subsidy to investment) must be used as well. The issue then becomes that of the joint determination of the optimal policies.

Finally, in the model, as in the original Holmström-Tirole contribution, it was assumed that although monitoring reduces entrepreneurial moral hazard (which facilitates access to credit), it had no impact on profitability. However, as discussed in Favara (2012) for instance, monitoring may also affect the quality (or value) of the projects that entrepreneurs choose to implement, by interfering ex ante in the selection process itself. Integrating this mechanism would provide an additional channel through which macroprudential regulation could affect growth and welfare. 


\section{References}

Agénor, Pierre-Richard, and Luiz Pereira da Silva, "Reserve Requirements and Loan Loss Provisions as Countercyclical Macroprudential Instruments," Policy Brief No. IDBPB-250, Inter-American Development Bank (February 2016).

_ - "Capital Requirements, Risk-Taking and Welfare in a Growing Economy," Working Paper No. IDB-WP-771, Inter-American Development Bank (March 2017).

Barnea, Emanuel, Yoram Landskroner, and Meir Sokoler, "Monetary Policy and Financial Stability in a Banking Economy: Transmission Mechanism and Policy Tradeoffs," Journal of Financial Stability, 18 (June 2015), 78-90.

Basel Committee on Banking Supervision, Basel III: The Liquidity Coverage Ratio and Liquidity Risk Monitoring Tools, Report No. 238 (January 2013).

Begenau, Juliane, "Capital Requirements, Risk Choice, and Liquidity Provision in a Business Cycle Model," unpublished, Harvard Business School (March 2015).

Bhattacharya, Joydeep, Mark G. Guzman, Elisabeth Huybens, and Bruce D. Smith, "Monetary, Fiscal, and Reserve Requirement Policy in a Simple Monetary Growth Model," International Economic Review, 38 (May 1997), 321-50.

Cerutti, Eugenio, Ricardo Correa, Elisabetta Fiorentino, and Esther Segalla, "Changes in Prudential Policy Instruments - A New Cross-Country Database," International Journal of Central Banking, 13 (March 2017), 477-503.

Chakraborty, Shankha, and Tridip Ray, "Bank-Based versus Market-Based Financial Systems: A Growth-Theoretic Analysis," Journal of Monetary Economics, 53 (March 2006), 329-50.

Christensen, Ian, Césaire Meh, and Kevin Moran, "Bank Leverage Regulation and Macroeconomic Dynamics," Working Paper No. 2011-32, Bank of Canada (December 2011).

De la Croix, David, and Philippe Michel, A Theory of Economic Growth: Dynamics and Policy in Overlapping Generations, Cambridge University Press (Cambridge: 2002).

Dewatripont, Mathias, and Jean Tirole, "Macroeconomic Shocks and Banking Regulation," Journal of Money, Credit and Banking, 44 (December 2012), 237-54.

Diamond, Douglas W., "Financial Intermediation and Delegated Monitoring," Review of Economic Studies, 51 (July 1984), 393-414.

Favara, Giovanni, "Agency Problems and Endogenous Investment Fluctuations," Review of Financial Studies, 25 (July 2012), 2301-42.

Fowowe, Babajide, "Financial Liberalization in Sub-Saharan Africa: What do we Know?," Journal of Economic Surveys, 27 (March 2013), 1-37.

Gale, Douglas, "Notes on Optimal Capital Regulation," in The Evolving Financial System and Public Policy, ed. by Pierre St-Amant and Carolyn Wilkins, Bank of Canada (Ottawa: 2004).

Haavio, Markus, Antti Ripatti, and Tuomas Takalo, "Macroeconomic Effects of Bank Recapitalizations," unpublished, Bank of Finland (December 2015).

Holmström, Bengt, and Jean Tirole, "Financial Intermediation, Loanable Funds, and the Real Sector," Quarterly Journal of Economics, 112 (September 1997), 663-91.

Jensen, Christian, "An Endogenously Derived AK Model of Economic Growth," published online, Macroeconomic Dynamics (June 2017). 
Mecagni, Mauro, Daniela Marchettini, and Rodolfo Maino, Evolving Banking Trends in Sub-Saharan Africa: Key Features and Challenges, IMF Publications (Washington DC: 2015).

Misati, Roseline N., and Esman M. Nyamongo, "Financial Liberalization, Financial Fragility and Economic Growth in Sub-Saharan Africa," Journal of Financial Stability, 8 (September 2012), 150-60.

Strulik, Holger, "A Note on Economic Growth with Subsistence Consumption," Macroeconomic Dynamics, 14 (November 2010), 763-71.

Taylor, Alan M., "Credit, Financial Stability, and the Macroeconomy," Working Paper No. 21039, National Bureau of Economic Research (March 2015).

Van den Heuvel, Skander J., "The Welfare Cost of Bank Capital Requirements," Journal of Monetary Economics, 55 (March 2008), 298-320. 
Figure 1

Equilibrium Investment

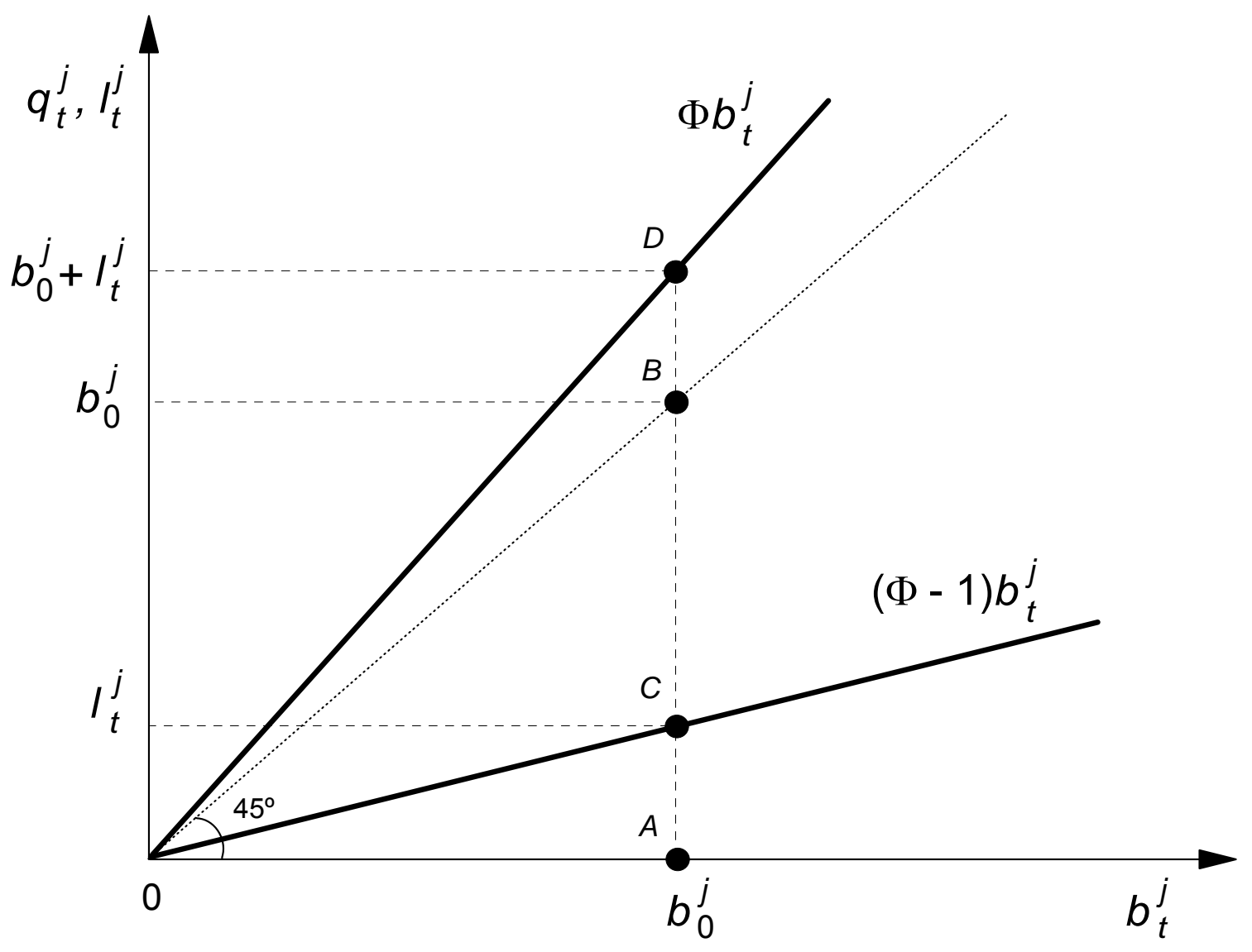


Figure 2

Optimal Monitoring Intensity and Growth-Maximizing Required Reserve Ratio

(Monitoring technology parameter $\varepsilon$ varying between 0.05 and 0.2 )

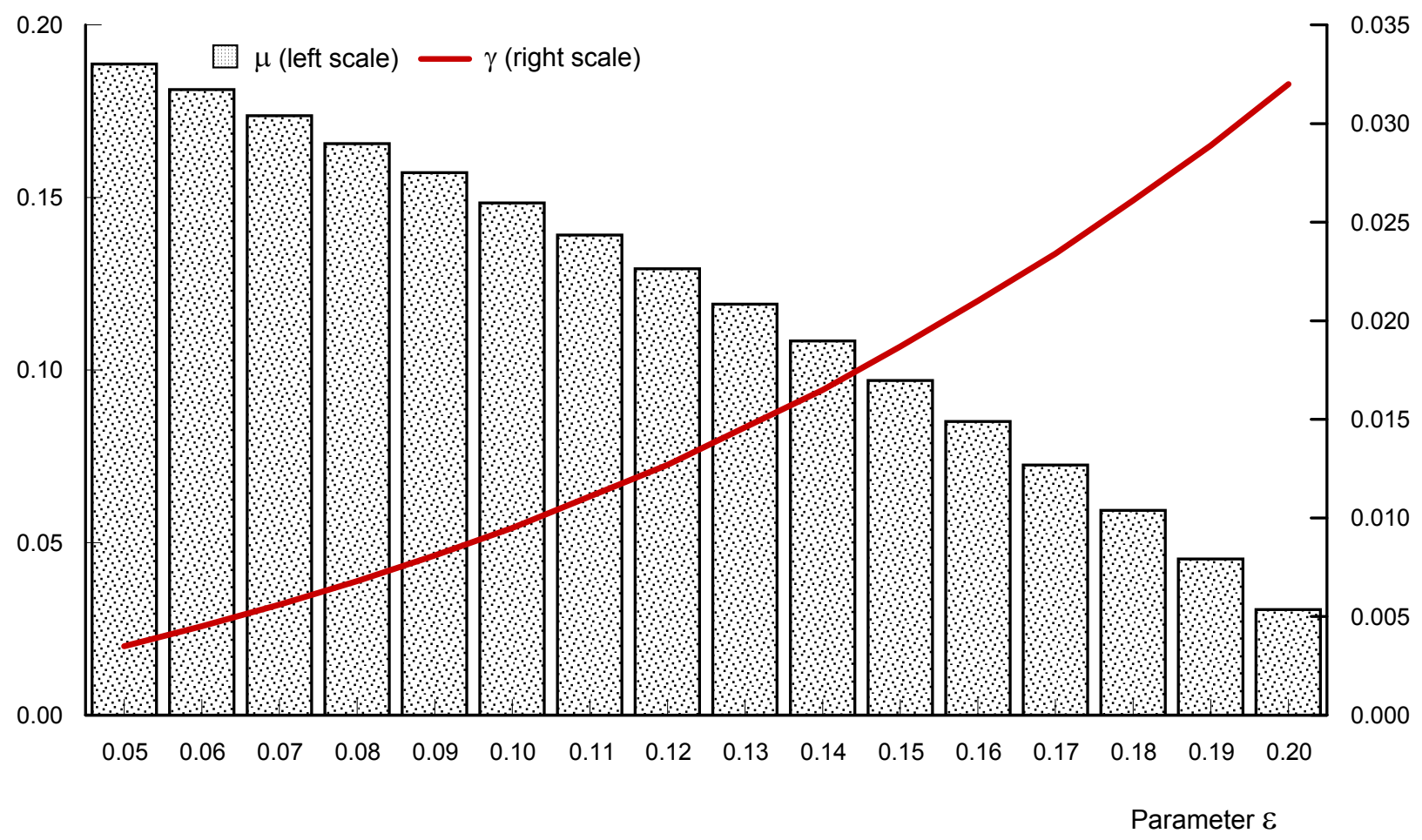

Source: Author's calculations. 